\title{
Measurements of everyday memory: Toward the prevention of forgetting
}

\author{
HERBERT F. CROVITZ \\ Veterans Administration Medical Center, Duke University, and Duke University Medical Center, \\ Durham, North Carolina
}

and

WALTER F. DANIEL

Veterans Administration Medical Center, Durham, North Carolina

\begin{abstract}
Data were taken from a separate study (Crovitz, Cordoni, Daniel, \& Perlman, in press). Young adults $(n=47)$ used memory diaries to record instances of forgetting that they noticed happened to them in everyday living. The gists of 1,000 consecutive reports of instances of forgetting were determined, and this paper reports the frequency distribution found. A table of the 33 types of forgetting that cover 492 of the 1,000 instances is given. From such lists, sets of reminder cues might be constructed and used in studies of the prevention of forgetting in specific groups (e.g., young vs. old, normal vs. brain-damaged or amnesic).
\end{abstract}

It would be desirable to have people of various ages list the full set of episodes of forgetting experienced in everyday living, as well as to observe other subject variables in a similar fashion. Such a set should include each time and date that people notice that they have forgotten anything, the things forgotten, and the cues that caused them to know they had forgotten. From such a list, subsets of forgetting incidents, arrayed by experienced frequency, could be constructed, and several theoretical and practical uses could be found (for an analogous case, see Crovitz \& Harvey, 1979, and Crovitz, Harvey, \& McKee, 1980).

\section{METHOD AND RESULTS}

One method for collecting data to create such a listing is to distribute memory diaries to people with the instruction that they record, for a period of 1 week, every time that they realize they have forgotten anything. Such a method should be sharply differentiated from questionnaire methods, in which people retrospectively estimate features of typical forgetting experiences (Cordoni, 1981; Herrmann, 1982; Herrmann \& Neisser, 1978). Retrospective questionnaires depend on judgment and long-term memory to a larger extent than does the diary method, in which items are to be recorded immediately, not estimated from long-term memory.

This paper reports such a listing based on a new content analysis of the first 1,000 entries in the memory diaries kept by 47 Duke University undergraduates and

This work was supported by the Medical Research Service of the Veterans Administration. The authors' mailing address is: VA Hospital, 508 Fulton Street, Durham, NC 27705. members of a community social club for adults (Crovitz, Cordoni, Daniel, \& Perlman, in press). When, according

Table 1

The Most Popular Gists and Their Frequencies $($ Sum $=492)$

\begin{tabular}{lc}
\hline \multicolumn{1}{c}{ Gist } & Frequency \\
\hline I forgot a person's name & 113 \\
I forgot to make a phone call & 73 \\
I forgot a phone number & 30 \\
I forgot to do this assignment & 22 \\
I forgot a conversation & 21 \\
I forgot to take a book & 18 \\
I forgot to take a letter & 17 \\
I forgot to give information & 14 \\
I forgot to take papers & 12 \\
I forgot a dream & 10 \\
I forgot to give a message & 9 \\
I forgot to set a clock & 9 \\
I forgot location of a book & 9 \\
I forgot location of keys & 9 \\
I forgot to take a card & 8 \\
I forgot to get money & 8 \\
I forgot location of a pen & 8 \\
I forgot what I was talking about & 8 \\
I forgot to do a letter & 7 \\
I forgot to get information & 7 \\
I forgot to go to a meeting & 7 \\
I forgot to take identification & 7 \\
I forgot to take checkbook & 6 \\
I forgot to take glasses & 6 \\
I forgot to take gloves & 6 \\
I forgot to take vitamins & 6 \\
I forgot the sports schedule & 6 \\
I forgot the name of a song & 6 \\
I forgot the number of a room & 6 \\
I forgot today's date & 6 \\
I forgot a definition & 6 \\
I forgot the time for a class & 6 \\
I forgot the time for a meeting & \\
\hline
\end{tabular}


to Basic English (Ogden, 1934), two raters agreed on the gist of a forgetting incident, the gist was put on a list. Table 1 shows that about half of the 1,000 episodes of forgetting could be reduced to a set of 33 gists.

\section{DISCUSSION}

Retrospective judgments of the remoteness of cued autobiographical memories are easily made (Crovitz \& Quina-Holland, 1976; Crovitz \& Schiffman, 1974). Data collected using such a retrospective method has been taken to bear on the question of the retention function for autobiographical memories (Rubin, 1982).

It is possible that the forgetting of current information (e.g., "a person's name") and current intentions concerning planned actions (e.g., "to make a phone call") will accelerate over time unless special steps are taken to prevent such forgetting.

In the set of memory diaries taken as a whole, about half the specific forgetting incidents concerned the forgetting of intentions (Harris \& Wilkins, 1982). Lists of extremely probable everyday intentions might be determined for people in various groups (e.g., young vs. old, normal vs. brain-damaged or amnesic, etc.), and the appropriate lists might then be used as reminder cues for people in the appropriate groups before they set out on a day's activities (Diller \& Gordon, 1981).

\section{REFERENCES}

Cordoni, C. N. (1981). Subjective perceptions of everyday memory failures. Unpublished doctoral dissertation, Duke University, Durham, NC.

Crovitz, H. F., Cordoni, C. N., Daniel, W. F., \& Perlman, J. (in press). Everyday forgetting experiences: Real-time investigations with implications for the study of memory management in brain-damaged patients. Cortex.

Crovitz, H. F., \& Harvey, M. T. (1979). Early childhood amnesia: A quantitative study with implications for the study of retrograde amnesia after brain injury. Cortex, 15, 331-335.

Crovitz, H. F., Harvey, M. T., \& McKee, D. C. (1980). Selecting retrieval cues for early-childhood amnesia: Implications for the study of shrinking retrograde amnesia. Cortex, 16, 305-310.

Crovitz, H. F., \& Quina-Holland, K. (1976). Proportion of episodic memories from early childhood by years of age. Bulletin of the Psychonomic Society, 7, 61-62.

Crovitz, H. F., \& Schiffman, H. (1974). Frequency of episodic memories as a function of their age. Bulletin of the Psychonomic Society, 4, 517-518.

Diller, L., \& Gordon, W. A. (1981). Interventions for cognitive deficits in brain-damaged adults. Journal of Clinical and Consulting Psychology, 49, 822-834.

Harris, J. E., \& Wilkins, A. J. (1982). Remembering to do things: A theoretical framework and an illustrative experiment. Human Learning, 1, 123-136.

HerrmanN, D. J. (1982). Know thy memory: The use of questionnaires to assess and study memory. Psychological Bulletin, 92, 434-452.

Herrmann, D. J., \& Neisser, U. (1978). An inventory of everyday memory experiences. In M. M. Gruneberg, P. E. Morris, \& R. N. Sykes (Eds.), Practical aspects of memory. London: Academic Press.

OGden, C. K. (1934). The system of Basic English. New York: Harcourt, Brace \& World.

Rubin, D. (1982). The retention function for autobiographical memory. Journal of Verbal Learning and Verbal Behavior, 21, 21-38.

(Manuscript received for publication May 17, 1984.) 